\title{
The Pre-acquisition Process of Counter-school Culture-A Case Study of Migrant Children School in Z Community
}

\author{
Leyi Zhou, Jingming Liu* \\ TsingHua University, the School of Social Science, Beijing, China \\ zhouleyi1121@gmail.com
}

Keywords: pre counter-school culture, migrant children

\begin{abstract}
Based on the theory of education inequality, education reproduction and counter school culture, this research use the method of deep interview to collect background information and do a field study in one migrant children school in $\mathrm{Z}$ community. On one hand, this study use the classic research paradigm on migrant children school and try to verify the classical theory under Chinese social background; on the other hand, this study focus on the group of students from Grade 6 and try to describe their special group culture. The study comes out with a preliminary conclusion that during the whole process of the forming counter-school culture, the stage of primary school plays the role of pre-acquisition.
\end{abstract}

\section{反学校文化的预备习得过程一基于Z社区打工子弟学校的个案研究}

\author{
周乐一，刘精明* \\ 清华大学社科学院社会学系, 北京, 中国 \\ zhouleyi1121@gmail.com
}

关键词: 反学校文化, 打工子弟

中文摘要: 本研究基于教育不平等理论/教育再生产理论以及反学校文化的抵制理论的相关综 述, 通过结构化访谈收集到的背景信息作为补充, 以威利斯的研究进路为标杆, 进入Z社区的 打工子弟小学展开田野研究。一方面参考以往研究的范式在打工子弟小学进行以验证为目的 研究, 另一方面将关注点放在打工子弟小学的六年级学生上, 尝试描述打工子弟小学 内部不 同年龄段学生的群体文化, 解释这一过度阶段打工子弟行为和心理上发生的变化及背后原因, 并发现打工子弟的阶级再生产过程并非在初中才真正作用, 初中阶段的反学校文化正式形成, 在再生产过程中是“主导”作用, 而小学阶段尤其是小学六年级阶段有对反学校文化开始预进 行“预备”习得，在再生产过程中是“铺垫性”作用。希望在之后进一步证实相关设想。

\section{1. 引言}

随着城市化和工业化进程的加快, 农村劳动力向城市转移并成为经济发展中的重要群体。 根据《中国流动人口发展报告 $2015 》$ 显示, 我国流动人口年均增长约 800 万人, 到 2020 年 总 数将达到近 3 亿人。从 20 世纪九十年代起, 这种劳动力转移由个人追求职业发展的流动向举家 迁移转变, 而农民工家庭中的儿童作为未来劳动力的重要组成部分, 其社会化过程 (学校教育) 成为影响社会流动与阶级固化的重要环节, 因此农民工随迁子女的教育问题也作为一项重 要 的社会学议题被学界高度关注。 
从保罗威利斯的《学做工》开始, 西方社会学对于底层阶级的研究开始关注行动者具体 表达了什么, 有何行动, 再生产了什么, 以及在再生产阶级位置的过程中扮演了什么角色。 而近年来国内关于农民工子弟校的研究也尝试进入具体的农民工子弟群体, 进入其学校行为 与文化生产中, 一方面比较农民工子弟学校内反学校文化与英国工人阶级小子群体的异同, 一方面探究在中国农民工子弟群体内部特有的文化核心。

笔者于2014年11月起每周前往北京市海淀区的Z社区服务中心做课后辅导班志愿者。除 课堂上的互动之外, 还参与日常家访活动, 与学生在课外交流。在做志愿者的过程中, 根据 笔者的长期观察以及社区工作人员的讲述, 六年级小学生在 $5 / 6$ 年级有一个很大的转变, 被社 区老师称为 “黑化” 和 “性情大变”。这一阶段班内会开始出现3-5人的小团体, 从原来的单 纯淘气转化为不尊重学校权威, 公然与老师作对; 男女生之间的矛盾从同桌之间的小打小闹变 成全班范围内划清界限的对立，一言不合就动手打群架; 在成绩不好作业不会时，从以前的惭 愧变成玩世不恭的自嘲。对比其他年龄段的孩子会发现, 此时的农民工小学内的不同年级之 间发展出不同文化, 且六年级内部出现了率先跟初中打工子弟学校反学校文化趋同的小团体。 这一小学时期转折点仿佛更像初中子弟们进入预备性信号。以往研究都进入社会再生产的现 场和农民工子弟群体内部做具体而深入的田野研究, 但是均以初中为主, 这让笔者开始思考: 反学校文化的形成是初中才开始的吗?六年级的突变为初中进入这种文化场域做了哪些准备? 小学和初中在再生产中的作用有何差异?带着这些疑问, 笔者继续参与社区中心的服务工作, 深入农民工子弟群体内部, 重点观察小学六年级阶段的农民工子弟同辈群体之间的互动特点 和文化特点, 解答疑惑。

\section{2. 文献综述}

\section{1 西方经典研究}

布迪厄的文化与教育再生产理论以 “符号暴力” 为逻辑基础, 将教育行动看为一种专断 权力所强加的一种文化专断, 是在实现文化再生产也是社会结构的再生产 (Bourdieu, P. , \& Passeron, J. C. , 1990)。文化在行动者本人并无察觉的情况下形成于特权阶层内部, 并与学校教 育的某种态度和能力相适宜, 也可说学校教育在一定程度上就是精英教育, 制造着精英阶级的 语言习惯、思维习惯和行为习惯。而这些习惯与流动儿童所长期接触的生活环境迥然相异, 学校教育貌似平等, 实则再 生产着社会与文化的不平等, 对一些人来讲, 学到精英文化是用很 大代价换来的成功; 对另一些 人来讲, 这只是一种继承 (Bourdieu, P. , \& Passeron, J. C., 2016)。 因此这样看来, 学校教育的作用在于将文化不断传递 给本阶层的下一代, 以 “遗传” 的方式 不停地对社会不平等进行再生产, 并使其合理化、固定化, 并且在这一过程中控制社会流动, 促使社会阶层固化 (Kang, J., 2013)。基于这一理论来看可知对于流动儿童来说, 灌输式的学习 内容超越他们直接接触的生活经验, 而同类群体生活状态又使得他们看不到良好变化的可能 性, 即所谓正面榜样的缺乏, 导致他们难以从周围环境中找到吸引他们努力求学的因素。在这 种状态下接受学校教育的时间越长, 越不利于他们的积极主动的做出改变自身社会地位的努 力, 这也为打工子弟年级越高对于学习越不重视的现象做出了一种合理的解释。因此文化再生 产理论要求不仅重视来自不同阶级与阶层受教育者在客观现实的落差, 也强调他们在行为决 策上的主观能动性。同样地, 看待打工子弟的学校教育不仅要从客观因素出发进行讨论, 也必 须重视主观因素的影响 (Zhu,W.,2006)。无论是从掌握文化的动机还是从学业成绩的期望上讲, 流动儿童都处于不利地位。这并非是由于流动儿童资质钝拙, 而是使用上层群体的标准来评判 来自底层的学生, 其本质是优势群体的特权造成的不平等事实。伯恩斯坦从语言技能的角度对 来自不同背景的教育现象做了深入分析, 提出在语言使用方面, 工人阶级子女使用的语言是

“限定符码” , 而中产阶级子女使用的则是 “精密符码” , 二者在适应正规学校教育方面的差 异也支持了上面的观点 (Han, D. , 2010)。除布迪厄的再生产理论之外, 威利斯的对抗文化再生 
产理论引出了反学校文化这一概 念。西方社会学领域对反学校文化的研究始于 20 世纪 60 年 代, 保罗威利斯在《学做工》中认为 正是孩子自己的文化让部分工人阶级子弟准备好了以体 力劳动的方式出卖劳动, 用真正的学习/肯定/占有/反抗来体验底层角色的诅咒。底层工人 阶级子弟已经洞察到了真正决定工人阶 级生存状态的先决条件, 这种自我纳入劳动的过程是 构成整个工人阶级文化更新的一个方面。威斯利通过研究说明工人阶级子弟从事发展前景有 限的工人工作, 并非是由于学业失败使他们认为自己 “低人一等” 而造成的, 他们并未因成为 工人而感到自卑甚至感到自得其乐, 他们之所以能够克服自卑心理, 主要得益于在校学习期间 创造的一种与蓝领文化十分相似的反学校文化, 这就揭示了 “工人阶级子女是如何获得工人 阶级工作的”，证明了学校教育中主观选择的文化再生产现象 (Han, D. , 2010)。威斯利描述中的 反学校文化在打工子弟群体中随处可见。流动儿童放弃学校教育对于自我的塑造之后, 作为补 偿则寻求到了反学校文化作为精神庇护。除威利斯之外, 许多学者对反学校文化也有不同解 释。功能主义视角下, 默顿的结构紧张论将反 学校文化定义为社会结构紧张之下的偏差行为; 科恩的亚文化理论认为中下层青少年的言行和 价值观不符合社会标准, 社会地位被否定, 导 致产生反学校文化, 与之对应贝克的标签理论则认为社会主流文化是通过制造对立来给亚文 化群体贴标签。冲突主义视角下除威利斯和布迪厄之外, 吉登斯和鲍尔斯则提出学校自身的 奖赏系统会禁止学生去表现对权威产生威胁的能力 (Deng, L. , 2003)。

\section{2 本土研究}

近年来，国内关于打工子弟教育问题的研究也开始走入学校这一再生产场所，探究具体 的再生产过程。石长慧在北京海淀区/朝阳区等打工子弟学校进行田野调查时发现私立打工子 弟学校的办学策略/管理策略阻碍了学生的阶层流动, 成为阶级再生产的场所。在打工子弟学 校, 存在着一种逆淘汰机制:有希望升学的品学兼优的学生会流出学校, 品行学业差的学生会 留在学校。这背后的原因主要在于, 打工子弟学校无资金支持与公办学校进行教育竞争, 在 “利益最大化”的办学策略之下，“有教无类”的招收尽可能多的学生并想方设法留住学生以取得 可观收入。例如, 学校会通过透题和纵容作弊的方式给学生一个漂亮的表面成绩让家长满 意, 同时让学生实际的学习能力较差, 从而不被城市里通过考试选拔优秀学生的公立学校所接收, 如此一来, 生源得到保证, 学校利益得到保证, 但学生自身向上流动的机会也被阻隔, 教育 使学生实现阶层流动的功能无法发挥 (Shi, C. , 2014)。

周潇在北京某打工子弟学校进行田野调查后发现, 在农民工子弟学校的反学校文化背后 是子弟们高度边缘化的生存状态, 这使得他们难以通过教育实现向上流动, 从而以拒绝知识 的形式放弃学业, 完成了社会再生产。相比于石长慧侧重学校管理和教育方式对阶级流动的 影响, 周潇的研究更倾向于分析子弟自我放弃流动机会的原因。他在田野调查中观察到子弟 们在学校拒绝学习, 对老师的管教无动于衷甚至找乐子调㑆教师, 他们的放荡不羁快乐自在 背后是空虚/失落和对未来出路的迷茫。从学习态度上, 子弟们在意识到现实和期待的距离之 后,父母和老师、仍然对于知识的价值持肯定态度, 但由于子弟在学校教育中被边缘化, 很能 获得真正向上流动的机会。从心理状态上，子弟们由于自己的外来者身份有很深的自卑感， 通过形式上的嬉笑打闹/挑战学校权威来掩盖心中的绝望, 虽然很想摆脱父母的身份实现向上 流动但却在内心自我否定。因此, 农民工劳动力再生产的低成本组织模式在将农民工子女边 缘化的同时, 使农民工子女在失去上升希望的情况下被迫放弃向上流动, 形成农民工身份的 再生产 (Zhou, X. , 2011)。

熊易寒在《底层-学校与阶级再生产》一文中则提出就读于公办学校的农民工子女在成 长过程中存在显著的天花板效应, 一方面认同主流价值观, 渴望向上流动, 另一方面则在与 外界的互动过程中对自身的前景产生了较低水平的预期(仿佛有一块天花板封住了自己向上 流动的空间从而主动放弃学业上的努力), 产生“制度性自我放弃”;而私立农民工子弟学校则盛 行反学校文化, 通过否定学校的价值系统/荋视校方和教师的权威来获得独立和自尊, 同时心 
甘情愿地提前进入次级劳动力市场, 加速阶级再生产的进程, 两类机制虽有差异但是都导向 阶级再生产而非社会流动 (Xiong, Y., 2008; Xiong, Y. , 2009)。而熊春文基于田野调查的结果进 一步提到, 农民工子弟并不是一个同质的社会群体, 不会一致性地做出反学校行为, 也不是 单枪匹马与正式制度 作战而是依附于一个个不同的同辈群体。具体而言，同辈群体会以“义” 为核心, 以友谊为纽带, 以“基础群体”“衍生群体”框架的群体生态为形式把左右成员都吸纳进 其势力范围之内, 每位成员都可能属于不同的群体获得不同维度和质感的社会化体验, 构成 打工子弟学校的实际社会基础, 通过组织群体活动彰显自己的自主性/能动性和主体性, 形成 清晰的反学校文化, 最终的结果是打工子弟们主动放弃学业, 结构和宏观上造成了社会再生 产 (Xiong, C. , Wang, X. , Zhe, X. , 2014; Xiong, C. , Liu, H. , 2014; Xiong, C. , Shi, X. , Wang, Y. , 2013)。

\section{3 研究设计与研究方法}

本研究基于教育不平等理论/教育再生产理论以及反学校文化的抵制理论的相关综述, 通过结构化访谈收集到的背景信息作为补充, 以威利斯的研究进路为标杆, 进入打工子弟小 学 展开田野研究。一方面致敬经典, 与理论对话, 参考以往研究的范式在打工子弟小学进行 以验 证为目的研究, 另一方面将关注点放在打工子弟小学的六年级学生上, 尝试描述打工子 弟小学 内部不同年龄段学生的群体文化, 解释这一过度阶段打工子弟行为和心理上发生的变 化及背后 原因。本研究选取了北京市Z社区进行。Z社区位于北京市近郊区某街道, 是一 个典型的外来 务工人员聚集地。这里有大批来自安徽、河南、河北、四川等地的农民工, 他 们在这里大多从 事装修、维修、物业、快递等工作。社区共有居民1100户，3000多口人。 人口十分密集。社区 内共有两所小学, 分别是私立的 J 学和公立的S小学分校。本研究的 研究对象是Z社区J 小学的 小学生, 年龄范围在9-12岁之间, 为小学3-6年级学生, 均为社区 住户。

研究方法上, 本研究采用访谈法, 参与观察法结合的调研方法。访谈法中, 笔者与同校的四 人结成小组进行有关打工子弟家庭教育/学校教育状况的结构化访谈; 参与观察法中, 笔者在 $\mathrm{Z}$ 社区服务中心担任志愿者老师, 在一年内对参加社区课 后活动的小学生进行参与观察, 收集 资料。分析方法上, 本研究主要的分析方法为个案分析法, 将一年内观察到的个案进行整理 分析, 借鉴保罗威利斯的研究思路, 描述打工子弟内部一个小群体的群体文化和行为特点。 同时结合国内外关于教育分层和反学校文化的文献与研究加深认识, 将结构化访谈所得到的 关于家庭教育/学校教育基本情况的信息, 作为背景资料辅助个案分析。

\section{3. 访谈与观察结果}

\section{1 访谈}

在对J 小学的打工子弟小学生进行结构化访谈的过程中, 共收集到 21 个样本(6个三年级, 5个四年级，5个五年级，5个六年级)。总体而言，各个年级的孩子对“学校课程难度如 何”“班 上纪律如何”“家长是否平时花足够时间进行辅导”等基本问题的回答答案差异不大，职业理想 也普遍过分理想化, 不同于认识到现实的初中生在反学校文化中表现出的对未来发展的悲观 心理, 符合以往研究中对小学生未来期望的研究结果。

三四年级和五六年级学生唯一看法差异较大的是在关于回乡的看法上。当被问道, “以 后想留在北京上学还是回家读书?”时, 三四年级的小朋友均没有明确的坚持和看法, 留京和 回乡均可。11人中仅有 1 人提到户口问题, 即能够意识到是否可以留京读书与自己的户口有 关。而五六年级的小朋友 10 人中 7 人次均表示想留在北京上学，因为北京“环境好”“教育资源 好”“工资高”“环境好”，都表达了很强烈的希望在北京上学并向上流动的意愿，意识到北京的 优势资源并初步形成上升期待, 虽然也都知道自己户口不在北京但是由于还没有真正因为户 籍问题面临限制, 所以认识较为模糊, “天花板效应”的两个条件(强烈的向上流动意愿, 认识 到无法上升的现实)已经正在形成。而6人次表达了自己不想离开北京是因为“不想和朋友分 
开”, 可以看出群体意识初步形成, 加上农民工子弟初中时期的就学也大多选择居住地附近几 所固定招收非京籍学生的打工子弟学校, 这种群体向心力为未来形成反学校群体文化奠定基 础。

除此之外, 访谈中3-6年级学生在回答“不上大学也可以挣大钱”/“做技术工人没什 么不 好”等等问题上态度差异较小，普遍在对未来的期望和信心上没有显著差异，都意识得到 读 书的重要, 有信心上大学并找到白领类而非蓝领类工作, 虽然对具体职业的认识很模糊, 但 总 体上肯定上学的重要意义，对未来充满信心，此时“反学校文化”在小学没有形成清晰可见的 意识形态。

\section{2 个案观察}

$\mathrm{J}$ 小学的四人小团体-Y同学, L同学, C同学, Z同学

\begin{tabular}{|c|c|c|c|c|}
\hline & 该六年级小群体的表现 & $\begin{array}{l}\text { 与反学校文化 } \\
\text { 的对应 }\end{array}$ & $\begin{array}{l}\text { 与反学校文化的差 } \\
\text { 异 }\end{array}$ & 差异背后的原因 \\
\hline $\begin{array}{l}\text { 对学校权 } \\
\text { 威和学习 } \\
\text { 的态度 }\end{array}$ & $\begin{array}{l}\text { 焦不起乘孩子，燋不起 } \\
\text { 老师 }\end{array}$ & 薷视学校权威 & $\begin{array}{l}\text { 乘孩子仍然不需要 } \\
\text { 迎合这一群体来保 } \\
\text { 证自己在学校的生 } \\
\text { 存, 好好学习在非 } \\
\text { 正式和正式制度中 } \\
\text { 都仍然是主流 }\end{array}$ & \multirow{3}{*}{$\begin{array}{l}\text { 1.环境的矛盾; 人 } \\
\text { 在小学环境, 心 } \\
\text { 向初中文化。 } \\
\text { 2.心态的模糊: 有 } \\
\text { 初中生引导和影 } \\
\text { 响, 但是还没有 } \\
\text { 完全进入反学校 } \\
\text { 文化的群体, 没 } \\
\text { 得到自在的感 } \\
\text { 觉。从小对于读 } \\
\text { 书的重视心理还 } \\
\text { 在。 } \\
\text { 3.信息接触的不 } \\
\text { 足: 开始意识到 } \\
\text { 上升流动渠道狭 } \\
\text { 窄但是还没有开 } \\
\text { 始经历小升初, } \\
\text { 缺乏事实经历验 } \\
\text { 证。 }\end{array}$} \\
\hline $\begin{array}{l}\text { 人际关系 } \\
\text { 与同辈群 } \\
\text { 体 }\end{array}$ & $\begin{array}{l}\text { 1.燋不起三四年级, 与低 } \\
\text { 年级害怕初中生不同, } \\
\text { 开始和年长的孩子接触 } \\
\text { 并玩要。 } \\
\text { 2.形成男生女生各自的 } \\
\text { 小群体, 有领袖 / 有群 } \\
\text { 体间的冲突矛盾, 巩固 } \\
\text { 团体凝聚力。 }\end{array}$ & 义气文化 & $\begin{array}{l}\text { 群体结构简单, 只 } \\
\text { 按照性别有划分, } \\
\text { 没有形成复杂的人 } \\
\text { 际关系网络, 不足 } \\
\text { 以为反学校文化的 } \\
\text { 形成提供社会基 } \\
\text { 础。 }\end{array}$ & \\
\hline 未来规划 & 嘻嘻哈哈说不知道 & $\begin{array}{l}\text { 以无所谓来掩 } \\
\text { 盖心中的不安 } \\
\text { 和绝望 }\end{array}$ & $\begin{array}{l}\text { 意识到未来上升存 } \\
\text { 在难度但是心态仍 } \\
\text { 然放松, 尤其是对 } \\
\text { 于初中可以继续留 } \\
\text { 在北京 “混” 的孩 } \\
\text { 子。 }\end{array}$ & \\
\hline
\end{tabular}

笔者从2014年11月开始在Z社区一家NGO做志愿服务。该NGO设立了关注打工子弟教育 的服务中心, 提供课后辅导课 程及周末兴趣班。由于NGO场地有限, 人力资源有限, 每年 能够提供免费服务的人数仅限于部分先报名的打工子弟学员, 在Z社区以来自 $\mathrm{J}$ 小学的学生为 主。

笔者在一年多的时间内, 以志愿者老师的身份做课后辅导的服务(学生在中心的教室内 完成作业, 志愿者提供答疑服务, 并适当补充课外知识和进行团体游戏活动)。在这一过程中, 笔者对来自 J 学六年级的一个四人小团体进行了长期观察, 发现他们身上体现出了许多反 学校文化的特质，但又与以往实证研究的发现有所不同。

以上表格对比了他们行为中与初中反学校文化相符和不符的地方:

首先, 在对学校权威和学习的态度上, 这个小群体表达了明确的对学校权威的若视-- 嘲 笑老师板书写的丑, 看到有同学的作业写得工整整齐被老师表扬也会不屑一顾地说“写那么好 有啥用还不如抄答案方便呢”。但乘孩子在学校仍然是主流, 不需要为了生存迎合亚文化, 与熊 春文笔下乘孩子为了在校内立足而迎合反学校文化的情况存在差异。

其次, 在人际关系方面, 这一群体不像低年级学生那样对初中小混混们绕道而行。在社 区中心的操场上, 经常有初中生打闹玩要, 甚至抽烟吵架, 连老师们都很害怕这群“小混混”, 
年级较低的孩子更是一看到初中生就往教室跑。但J小学小团体中的Z同学等人会开始主动和 初中生接触,在被接纳后每次打招呼也变成点头或者默契一笑, 显然已经开始融入初中小混混 群体。在男女关系上, 也从之前的小打小闹演变为形成各自群体, 有领袖, 在发生矛盾时团 体作战。有一次, $\mathrm{C}$ 同学与一位叫 $\mathrm{S}$ 的女生因为起外号的问题发生争执, $\mathrm{Y}$ 同学直接拿着扫把 带着这一四人小团体和S为首的六年级女生互骂互打。许多不知情或者对争执原因并不了解 的六年级同学也加入到群体内, 为自己的朋友出气, 这与反学校文化中描述的“义气文化”相 符。但此时的群体结构只有性别划分，没有更复杂的人际网络，例如女生内部的“闺蜜”圈， 男女生之间形成的 “兄妹” 圈都未形成, 不足以为反学校文化的持续延伸和占据主导起推动作 用。

最后, 是对于未来的规划。一次聊天中, 笔者问 C同学等人“六年级毕业后留在北京读 书吗?”，C同学回答“你猜啊”，紧接着四个人都开始嘻嘻哈哈的笑。这可以理解为以无所谓的 态度掩盖心中对未来的不确定, 但对于尚未真正面对升学关口的六年级学生而言, 尽管意识 到未来上升存在难度但是心态仍然是“能混几天混几天”, 而初中生往往有过小升初的经历所 以会对体制内上升难度有直观体验。

\section{4. 反学校文化的预备习得过程}

综上可以发现, 六年级小学生的行为和群体关系已经向打工子弟初中生的反学校群体 文化靠近, 但是这种反学校文化仍未成型。究其原因, 首先是环境限制--六年级打工子弟仍 在小学, 没有直接接触初中文化的机会, 且只有一小部分学生率先与初中生群体接触, 但也 没有真正融入其中。其次是心态上还没有形成对反学校文化的“自豪感”和“自在感”，与小学 校内重视知识的心态一致, 对校园权威的反抗更多像是一种模仿大孩子的行为, 较为表面化。 最后是信息接触的不足使得六年级孩子对于“上升通道变窄”没有亲身体会，“天花板效应”没 能完全产生作用。

相比于五年级以下的学生, 六年级的打工子弟反抗学校权威, 对自己散漫的行为有自己 的一套说辞, 进行学习观念的重塑; 形成群体基础, 用自己出格和逆反的行动与小学低年级学 生“划清”界限, 开始营造自己的群体文化; 意识到上升机会受阻, 用无所谓的态度嘻嘻哈哈掩 盖内心恐慌。尽管这些特质尚未以意识形态的形式在校园内占据主导，但至少可以看出:表现 出这些特点的六年级学生已经率先与初中生融合, 被初中生文化群体接纳。因此, 打工子弟 的阶级再生产过程并非在初中才真正作用, 初中阶段的反学校文化正式形成, 在再生产过程 中是“主导”作用, 而小学阶段尤其是小学六年级阶段有对反学校文化开始预进行“预备”习得, 在再生产过程中是“铺垫性”作用。六年级打工子弟身上的突变像是在为未来进入初中适应反 学校文化做准备, 是像军队预备役一样, 打工子弟小学六年级的学生也正在经历反学校文化 在反抗权威/群体关系/未来期望三个方面特质的“预备”习得。

\section{致谢}

感谢清华大学社会学系刘精明老师对本研究的指导, 感谢Z社区NGO中Y老师和Z老师对 我研究的全程支持。

\section{References}

[1] Bourdieu, P., \& Passeron, J. C. (1990). Reproduction in education, society and culture (Vol. 4). Sage.

[2] Bourdieu, P., \& Passeron, J. C. (2016). Les héritiers: les étudiants et la culture. Minuit. 
[3] Kang,J.(2013).Thoughts of migrant children's education, based the theory of cultural reproduction-reading report of Bourdieu's 'Les héritiers: les étudiants et la culture'.China Education Innovation Herald.

[4] Zhu,W.(2006).The sociological analytical framework of educational inequality.Social Science.

[5] Han,D.(2010).The inequality in migration

[6] Deng,L.(2003).The categories and factors of counter school culture in junior high school-based on the study of GuangZhou.Guang Zhou Univeristy; Zhao,X.(2004).The commentary of western counter school culture. Journal of Shanghai Education Research.

[7] Shi,C.(2014).Identity and location-The social integration of migrate children in Beijing.

[8] Zhou,X.(2011).The comparison of counter school culture and class reproduction: a comparison of "XiaoZi"and"ZiDi”.Society. L.

[9] Xiong,Y.(2008).The identity and political socialization in contemporary China: an empirical study of migrate children. Fudan University; Xiong,Y. The school of bottom class and the class reproduction; Xiong, Y.(2009).Children in the process of urbanization - the self-identity and the acknowledge of urban and rural difference. Chinese Rural Economy

[10]Xiong,C.,Wang,X.,Zhe, X.(2014),Dawdle - a kind of understanding of migrate children's school culture. Journal of Nanjing Tech University(Social Science Edition);Xiong, C. ,Liu, H.(2014).Institutional self-abandonment and self-choosing - a case study of migrate children's school culture.Peking University Education Review;Xiong,C.,Shi,X.,Wang,Y.(2013).The double experience of personal loyalty - the group culture and social meaning of migrate children,Peking University Education. 